Provided for non-commercial research and education use. Not for reproduction, distribution or commercial use.

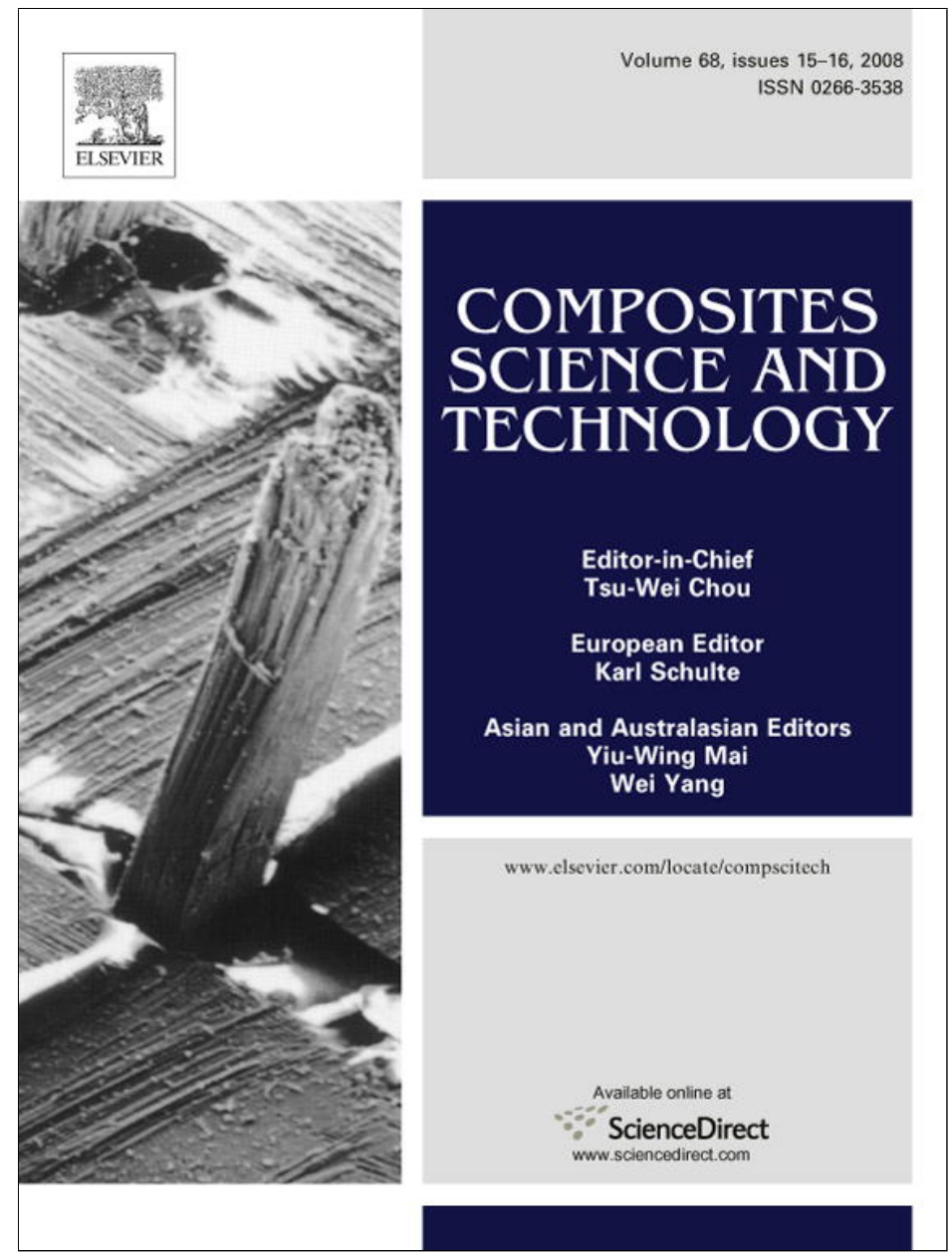

This article appeared in a journal published by Elsevier. The attached copy is furnished to the author for internal non-commercial research and education use, including for instruction at the authors institution and sharing with colleagues.

Other uses, including reproduction and distribution, or selling or licensing copies, or posting to personal, institutional or third party websites are prohibited.

In most cases authors are permitted to post their version of the article (e.g. in Word or Tex form) to their personal website or institutional repository. Authors requiring further information regarding Elsevier's archiving and manuscript policies are encouraged to visit:

http://www.elsevier.com/copyright 


\title{
Composites based on acylated cellulose fibers and low-density polyethylene: Effect of the fiber content, degree of substitution and fatty acid chain length on final properties
}

\author{
Carmen S.R. Freire ${ }^{\mathrm{a}, *}$, Armando J.D. Silvestre ${ }^{\mathrm{a}}$, Carlos Pascoal Neto ${ }^{\mathrm{a}}$, Alessandro Gandini ${ }^{\mathrm{a}}$, \\ Loli Martin ${ }^{\mathrm{b}}$, Iñaki Mondragon ${ }^{\mathrm{b}}$ \\ a Department of Chemistry and CICECO, Campus de Santiago, University of Aveiro, 3810-193 Aveiro, Portugal \\ ${ }^{\mathrm{b}}$ Escuela Universitaria Politécnica, Dpto. Ingeniería Química y del Medio Ambiente, 20018 Donostia-San Sebastián, Spain
}

\section{A R T I C L E I N F O}

\section{Article history:}

Received 14 July 2008

Received in revised form 2 September 2008

Accepted 9 September 2008

Available online 15 September 2008

\section{Keywords:}

A. Fibers

B. Mechanical properties

B. Thermal properties

B. Surface treatments

Fatty acids

\begin{abstract}
A B S T R A C T
Low-density polyethylene was filled with unmodified and fatty acid (hexanoic, dodecanoic, octadecanoic and docosanoic acids) esterified cellulose fibers. The thermal and mechanical properties, morphology and the water absorption behavior of the ensuing composites were investigated. The chemical modification of the cellulose fibers with fatty acids clearly improved the interfacial adhesion with the matrix and hence the mechanical properties of the composites and decreased their water uptake capacity. The performance of the composites was strongly affected by the degree of substitution (DS) and the fatty chain length as indicated by the fact that esterified cellulose fibers with low DS gave composites with better mechanical properties.
\end{abstract}

(c) 2008 Elsevier Ltd. All rights reserved.

\section{Introduction}

The remarkable properties of cellulose, the most abundant naturally available polymer, and also of its derivatives, have been exploited for centuries and new potential applications for this ubiquitous renewable resource are still being hunted, mainly in response to the predicted dwindling of fossil resources, their skyrocketing prices and to the increasing interest in the development of biodegradable materials based on renewable resources [1,2].

One of these ongoing investigations concerns the use of cellulose fibers as reinforcing elements in composite materials based on polymeric matrices [3]. The major problems faced by researchers in this field are mostly related with the highly polar surface of the cellulose fibers, which causes (i) a very low interfacial compatibility with non-polar matrices like polyolefins (ii) moisture uptake and (iii) inter-fiber aggregation by hydrogen bonding. Numerous strategies have been explored to overcome these drawbacks, mostly involving specific surface treatments of the fibers aimed at reducing its polar character, which include both physical and chemical modifications [3].

For example, the acylation of cellulose fibers with fatty acids [4-9] represents an interesting way to prepare reinforcing elements for composites with common thermoplastic matrices, such

\footnotetext{
* Corresponding author. Tel.: +351 234370695.

E-mail address: cfreire@ua.pt (C.S.R. Freire).
}

as polyethylene (PE). This strategy is particularly relevant because of the renewable and biodegradable nature of fatty acids and, of course, of their predominantly non-polar nature. However, only a few studies on the preparation and characterization of composites with cellulose fibers esterified with fatty acids and PE have been published thus far [10-12]. These studies considered only fatty acid derivatives with $\mathrm{C} 11 / \mathrm{C} 18$ and $\mathrm{C} 12 / \mathrm{C} 18$ aliphatic chains, respectively, neglecting important parameters, such as the degree of substitution (DS), fibers morphology and the fatty chain length.

As part of a wider research project on the heterogeneous chemical modification of cellulose fibers [6,7,13-16] for new applications (composites, paper materials, etc) we have been studying the preparation and characterization of composite materials based on acylated cellulose fibers and low-density polyethylene (LDPE). In this investigation, cellulose fibers modified with different fatty acids (C6, C12, C18 and C22) and different DS were investigated. The thermal and mechanical properties, the morphology and the water absorption behavior of the ensuing composites were evaluated.

\section{Experimental section}

\subsection{Materials}

The cellulose fibers used in this study were in the form of industrial Eucalyptus globulus ECF (Elemental Chlorine Free) bleached 
kraft pulp, kindly provided by a Portuguese pulp mill. The fatty acids (hexanoic C6 99\%, dodecanoic C12 99\%, octadecanoic C18 $95 \%$ and docosanoic C22 $\geqslant 80 \%$ ), low-density polyethylene (LDPE), thionyl chloride, pyridine, toluene and $N, N$-dimethylformamide (DMF), were supplied by Sigma-Aldrich. Toluene was dried with sodium wire. Pyridine and dimethylformamide (DMF) were purified by distillation over sodium hydroxide.

\subsection{Fibers modification}

The details related to the preparation of the acid chlorides by the standard reaction of the corresponding fatty acids with thionyl chloride, the heterogeneous esterification reactions in both media (toluene and dimethylformamide) and the determination of the degree of cellulose substitution (DS) have already been described $[6,17]$. The conditions associated with all the modifications are summarized in Table 1 .

\subsection{Compounding and processing}

Composites were prepared by compounding the polymeric matrix with the unmodified and acylated cellulose fibers in a melting mixer (Haake Rheomix 600P) working at $170^{\circ} \mathrm{C}$. Firstly, LDPE pellets were charged and, after melting, dried fibers were added. The systems were mixed during $7 \mathrm{~min}$ at $100 \mathrm{rpm}$. In order to study the effect the fatty acid chain length, the reaction solvent and the DS on the composite properties, a $30 \mathrm{wt}$ \% of fibers was used. The loading of modified fibers (C121hT) was also varied from 15 to $70 \mathrm{wt} . \%$ in order to study the effect of fiber loading.

Subsequently, the composites were molded, in an injection molding machine (Thermo-Haake Minijet II) for tensile (bar according to ISO 527-2-5A) and DMA analysis.

\subsection{Composites characterization}

The composites were characterized using Thermogravimetry (TGA), Differential Scanning Calorimetry (DSC), Dynamical Mechanical Analysis (DMA), Tensile tests, Scanning Electron Microscopy (SEM) and water absorption tests.

TGA essays were carried out with a Shimadzu TGA 50 analyzer equipped with a platinum cell. Samples were heated at a constant rate of $10^{\circ} \mathrm{C} / \mathrm{min}$ from room temperature to $800{ }^{\circ} \mathrm{C}$, under a nitrogen flow of $20 \mathrm{~mL} / \mathrm{min}$. The thermal decomposition temperature

Table 1

Degree of substitution (DS) of the acylated cellulose fibers (the abbreviations refer the fatty acyl chain lengths, the solvent used and the reaction time, e.g. C6T1h, refers the

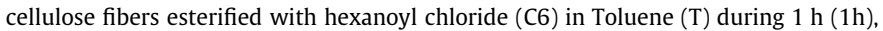
in the case of fibers modified in DMF a constant reaction time of $6 \mathrm{~h}$ was used)

\begin{tabular}{|c|c|c|c|c|}
\hline Cellulose fibers identification & FA & Solvent & Reaction time (h) & DS \\
\hline Cellulose & - & - & - & - \\
\hline C6T1h & C6 & Toluene & 1 & 0.42 \\
\hline C6T2h & & & 2 & 0.79 \\
\hline C6T6h & & & 6 & 0.53 \\
\hline C6DMF & & DMF & 6 & 1.26 \\
\hline C12T1h & $\mathrm{C} 12$ & Toluene & 1 & 0.61 \\
\hline C12T6h & & & 6 & 1.17 \\
\hline C12DMF & & DMF & 6 & 1.28 \\
\hline C18T2h & C18 & Toluene & 2 & 0.07 \\
\hline C18T6h & & & 6 & 0.24 \\
\hline C18DMF & & DMF & 6 & 1.23 \\
\hline $\mathrm{C} 22 \mathrm{~T} 2 \mathrm{~h}$ & $\mathrm{C} 22$ & Toluene & 2 & 0.01 \\
\hline C22T6h & & & 6 & 0.07 \\
\hline C22DMF & & DMF & 6 & 1.01 \\
\hline
\end{tabular}

was taken as the onset of significant $(\geqslant 0.5 \%)$ weight loss, after the initial moisture loss.

DSC thermograms were obtained in a Mettler-Toledo DSC822e apparatus calibrated with indium and equipped with a Haake EK90/MT intracooler system. The samples (5-10 mg) were analyzed by heating-cooling cycles between -60 and $150{ }^{\circ} \mathrm{C}$, under nitrogen at a scan rate of $20^{\circ} \mathrm{C} / \mathrm{min}$ using $40 \mu \mathrm{L}$ aluminum standard pans.

DMA measurements were carried out with a Tritec 2000 DMA Triton equipment, in the bending (single cantilever) mode. Tests were performed at $1 \mathrm{~Hz}$ and the temperature was varied from 25 to $100{ }^{\circ} \mathrm{C}$ by $4{ }^{\circ} \mathrm{C}$ steps.

Mechanical analyses were performed at room temperature in an Instron Universal Tester, model 4206, according to ASTM D 638 for tensile tests, using a load cell of $1 \mathrm{kN}$. The data acquisition rate was $10.0 \mathrm{~Hz}$ and the deformation rate $5 \mathrm{~mm} / \mathrm{min}$.

SEM micrographs of the composite fractured surfaces were obtained with a SU-70 equipment operating at $4 \mathrm{kV}$.

\subsection{Water uptake}

Composite samples (dimensions $60 \times 10 \times 1 \mathrm{~mm}$ ) were immersed in distilled water at room temperature to study their water uptake. A minimum of three samples were tested for each composite material. The weight increase due to water absorption was periodically assessed for $\sim 3$ months. Samples were taken out of the water, the wet surfaces were immediately wiped dry, weighted and then reimmersed in water. The water uptake at time $t, W_{\text {uptake, }}$ was calculated as:

$W_{\text {uptake }}=\left(\frac{W_{t}-W_{0}}{W_{0}}\right) \times 100 \%$

Where $W_{0}$ is the specimen initial weight and $W_{t}$ the specimen weight after an immersion time $t$.

\section{Results and discussion}

The composites prepared in this study were in general homogenous, except those with unmodified cellulose fibers, which showed some fiber agglomeration. All composites were characterized in terms of thermal and mechanical properties, morphology and water uptake capacity.

\section{Thermal properties}

The cellulose-based LDPE composites showed, in most cases, TGA profiles that were a combination of those of the corresponding cellulose fibers and matrix (Fig. 1) and were always less stable than the unfilled LDPE because of the presence of the natural fibers.

The composites with unmodified fibers gave a thermal degradation profile that was a perfect sum of those of the separated components, indicating that they degraded independently (Fig. 1). These results were a clearly evidence of the poor compatibility, i.e. bad interfacial adhesion, between the unmodified cellulose fibers and the PE matrix. Conversely, the composites with esterified cellulose fibers displayed an intermediate thermal behavior, which involved the expected different weight losses, associated with the two elements of the composite, but also a considerable increase in the thermal stability of the fibers, accompanied by a slightly decrease in the Tdmax (maximum decomposition temperature) of the PE matrix (Fig. 1). These results were a first indication of the good adhesion between the esterified cellulose fibers and PE matrix.

DSC thermograms of all the cellulose-based LDPE composites showed an endothermic peak ascribed to the melting of the crys- 
talline domains of the matrix, with a maximum at about $109^{\circ} \mathrm{C}$ (Table 2). The incorporation of both unmodified and acylated cellulose fibers did not significantly affect the melting temperature, regardless of the fiber content and fatty acyl chain length. This behavior had already been observed with other natural fiber-based composites $[12,18,19]$.

As expected, the enthalpy of fusion $\left(\Delta H_{\mathrm{m}}\right)$ decreased with the fiber loading (PEC12T1h series) due to the corresponding decrease in the amount of matrix. However, for composites with the same reinforcement content (30\%), $\Delta H_{\mathrm{m}}$ was poorly affected by the fatty acid chain length and by the DS. A slight decrease was only observed for composites with cellulose fibers bearing high DS values, namely all those modified in DMF and the C12/toluene sample.

Moreover, the degree of crystallinity of the composite materials was not detectably affected by the fiber content and properties.

\section{Mechanical properties}

The dynamic mechanical measurements were performed for LDPE composite materials filled with $30 \%$ of either unmodified or modified cellulose fibers, and with different fiber contents $(15 \%$, $30 \%, 50 \%$ and $70 \%$ ) for the cellulose fibers modified with $\mathrm{C} 12$ (C12T1h). The curves of the $\log \left(E^{\prime} / \mathrm{Pa}\right)$ (storage tensile modulus)
Table 2

Melting temperature $\left(T_{\mathrm{m}}\right)$, melting enthalpy $\left(\Delta H_{\mathrm{m}}\right)$ and degree of crystallinity $\left(\mathrm{X}_{\mathrm{c}}\right)$ of LDPE-based cellulose composites obtained from the DSC curves

\begin{tabular}{|c|c|c|c|c|c|}
\hline & Fatty acid & Fiber loading & $T_{\mathrm{m}}\left({ }^{\circ} \mathrm{C}\right)$ & $\Delta H_{\mathrm{m}}\left(\mathrm{J} \mathrm{g}^{-1}\right)$ & $X_{\mathrm{c}}(\%)$ \\
\hline PE & - & - & 109 & 94.0 & 33 \\
\hline PECellulose & - & 30 & 109 & 69.7 & 35 \\
\hline PEC6T1h & & 30 & 109 & 71.7 & 36 \\
\hline PEC6T2h & C6 & 30 & 109 & 68.7 & 34 \\
\hline PEC6T6h & & 30 & 109 & 73.8 & 37 \\
\hline PEC6DMF & & 30 & 109 & 65.7 & 33 \\
\hline PEC12T1h & & 30 & 109 & 68.5 & 34 \\
\hline PEC12T6h & $\mathrm{C} 12$ & 30 & 109 & 69.6 & 35 \\
\hline PEC12DMF & & 30 & 110 & 65.0 & 33 \\
\hline PEC18T2h & & 30 & 109 & 64.9 & 33 \\
\hline PEC18T6h & $\mathrm{C} 18$ & 30 & 111 & 63.5 & 32 \\
\hline PEC18DMF & & 30 & 110 & 62.1 & 31 \\
\hline PEC22T2h & & 30 & 110 & 66.1 & 33 \\
\hline PEC22T6h & $\mathrm{C} 22$ & 30 & 109 & 64.7 & 32 \\
\hline PEC22DMF & & 30 & 109 & 52.8 & 27 \\
\hline PEC12T1h15 & & 15 & 109 & 80.6 & 33 \\
\hline PEC12T1h30 & $\mathrm{C} 12$ & 30 & 109 & 66.9 & 34 \\
\hline PEC12T1h50 & & 50 & 109 & 47.7 & 33 \\
\hline PEC12T1h70 & & 70 & 108 & 28.6 & 33 \\
\hline
\end{tabular}
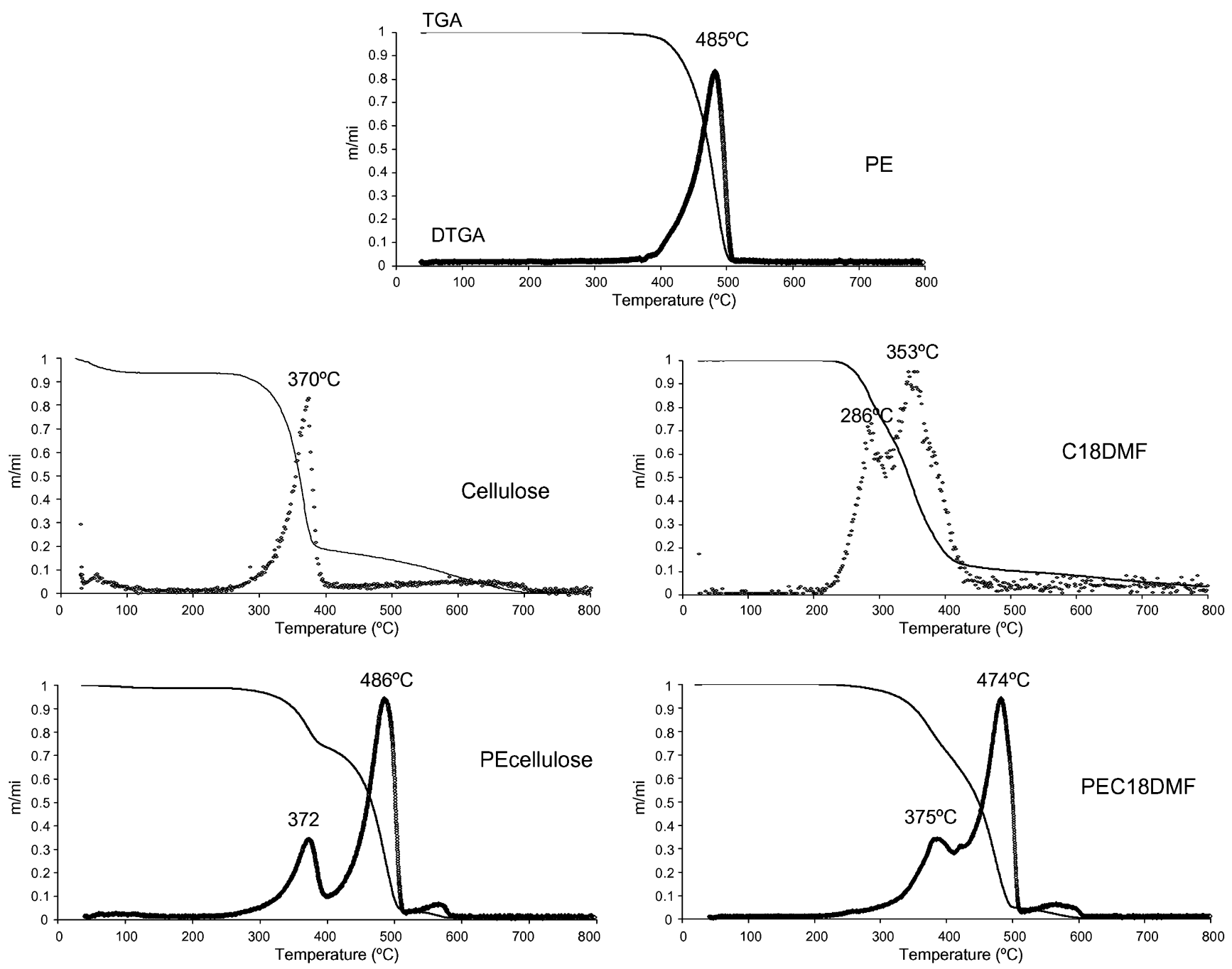

Fig. 1. Thermograms of unmodified and C18 esterified cellulose-based LDPE composites. 
vs. temperature at $1 \mathrm{~Hz}$ are displayed in Fig. 2, which incorporates as reference that obtained with the unfilled matrix. DMA experiments were only performed in the temperature range $25-100{ }^{\circ} \mathrm{C}$ (rubbery plateau) [20].

At room temperature, the amorphous domains of the matrix were in the rubbery state, and their crystalline regions acted as physical crosslinks, resulting in a high storage modulus. This rubbery modulus is known to depend on the degree of crystallinity of the material. It was observed that the storage modulus decreased gradually with increasing temperature, due to the increasing movement of amorphous domains of PE. The experiments were ended just before the melting of the crystalline zones.
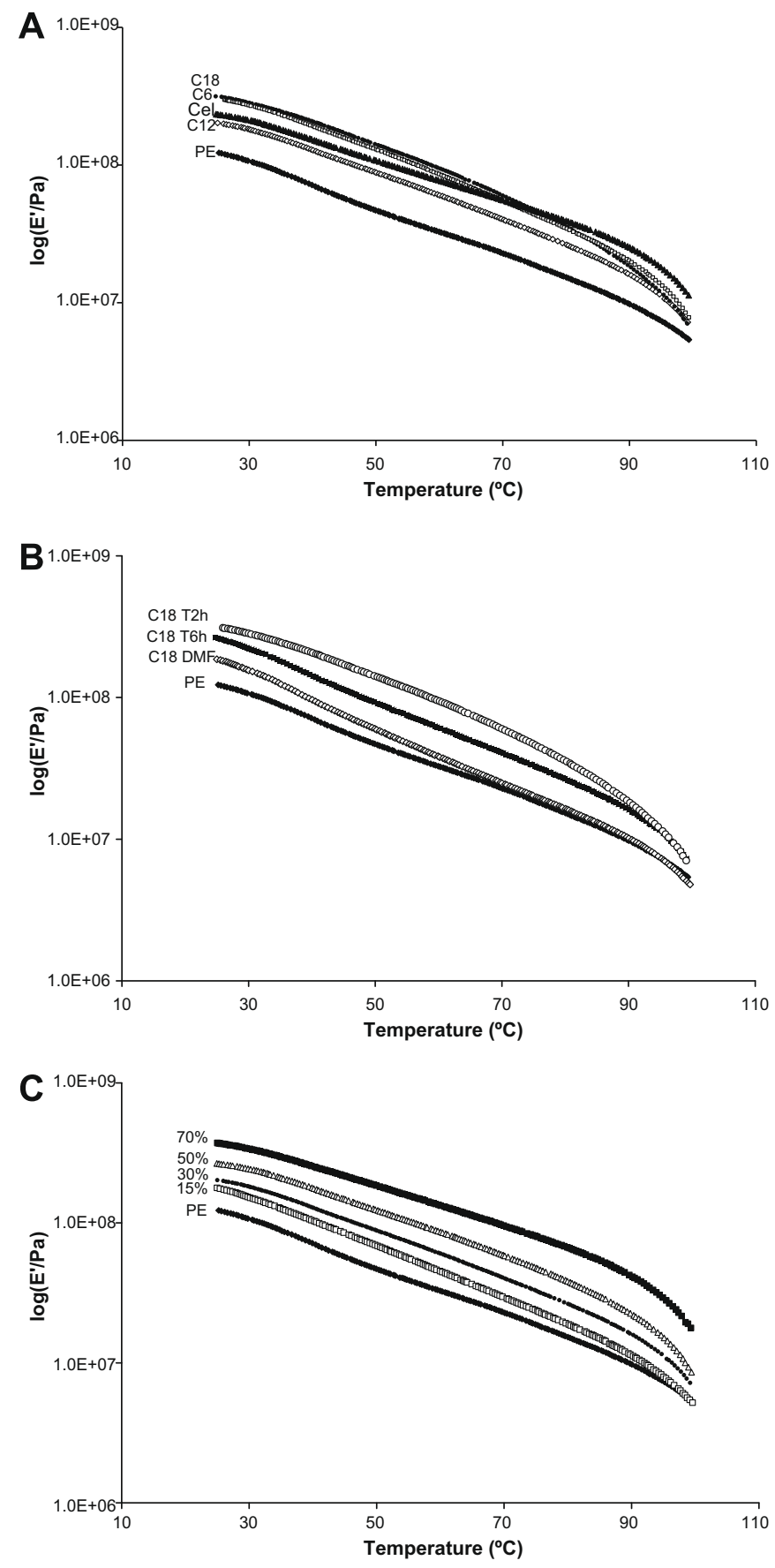

Fig. 2. Logaritm of the storage modulus $E^{\prime} v s$. temperature (at $4 \mathrm{~Hz}$ ) for cellulose fibers/LDPE composites: (A) effect of fatty acid chain length, (B) effect of the DS and (C) effect of fibers charge.
The addition of $30 \mathrm{wt} . \%$ of unmodified or acylated cellulose fibers to the LDPE matrix led in all cases to an increase in the storage modulus. However, this effect was strongly dependent on the fiber properties. The expected reinforcing effect depended on two main factors, viz (i) the quality of the adhesion between both components, which induces the efficiency of the stress transfer from the matrix to the fibers and (ii) the fiber aspect ratio $(L / d, L$ being their average length and $d$ their average diameter). Here, the composites filled with cellulose fibers modified in toluene, for $1 \mathrm{~h}$, except those with $\mathrm{C} 12$, presented a higher dynamic mechanical modulus than their counterparts with unmodified fibers (Fig. 2A), which obviously arose from the better interfacial adhesion between the modified fibers and the matrix. In this case, the aspect ratio did not play an important role because, for the same fatty acid, the esterified fibers with a lower DS preserved essentially the features of the native fibers, such as crystallinity and fiber length. On the other hand, for composites filled with cellulose fibers modified in toluene for long reaction times (6 h) and in DMF, the increase in the storage modulus was, in most cases, lower than that observed with
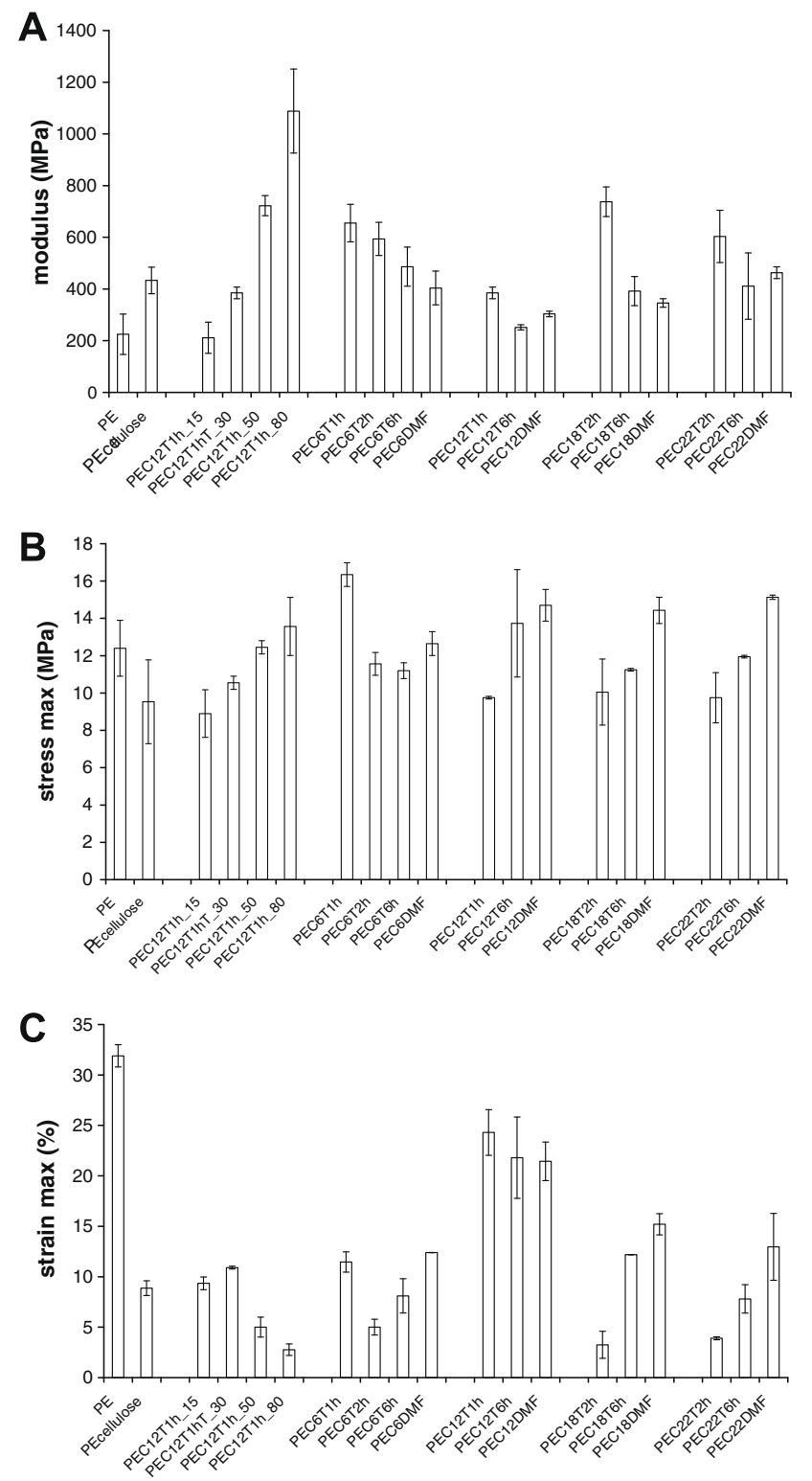

Fig. 3. Young's modulus (A), tensile strength (B) and elongation at break (C) of all cellulose-based LDPE composites studied. 

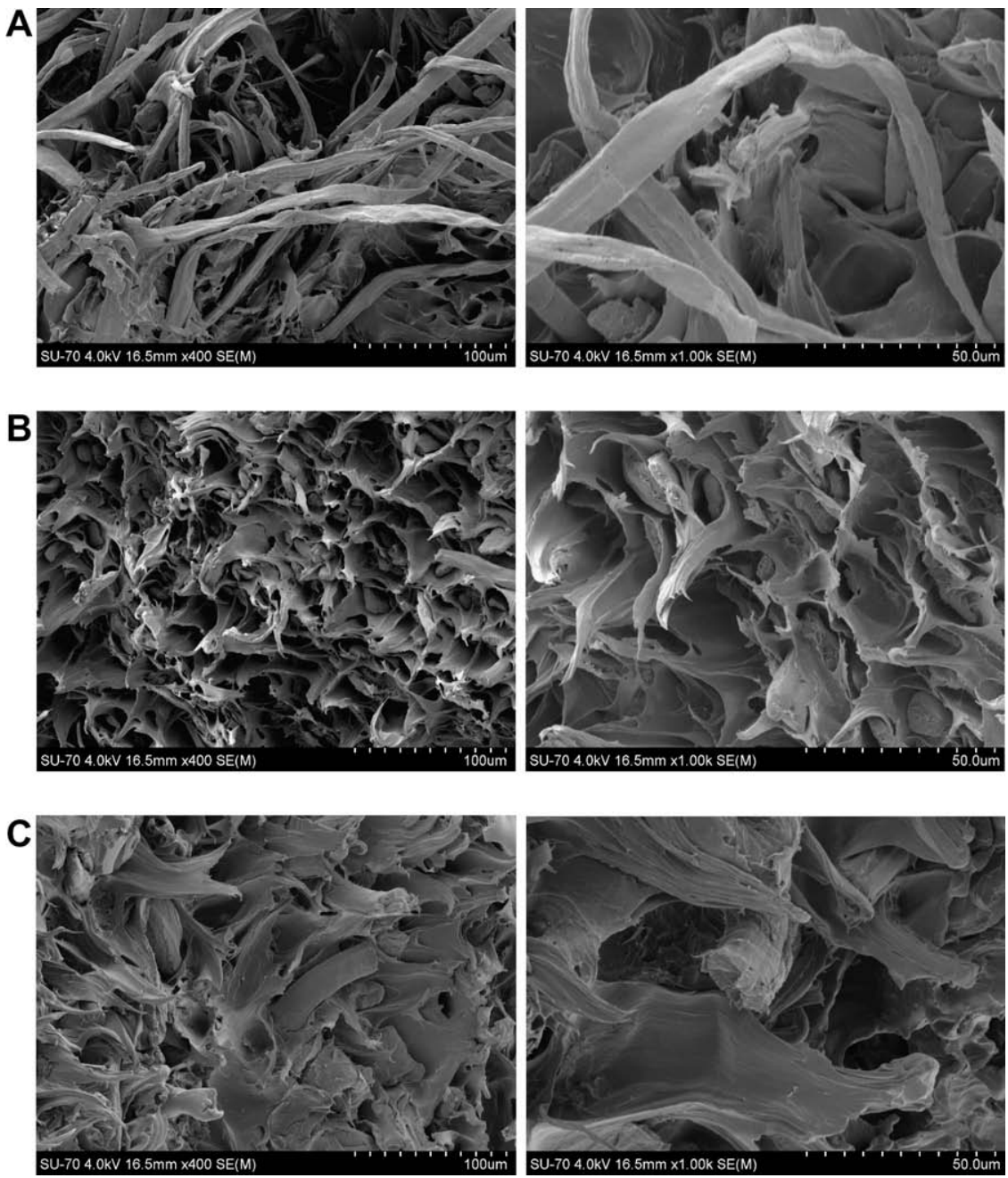

Fig. 4. Scanning electron micrographs of the fractured surfaces of cellulose fibers/LDPE composites, resulting from the tensile tests: (A) PECellulose, (B) PEC6T1h and (C) PEC18DMF.

the unmodified fiber counterparts (Fig. 2B). It seems that in this case, the aspect ratio played the major role on the mechanical properties of the PE-composites, since severe reaction conditions (time and the use of a swelling solvent) increased the DS, but led, in general, to a considerable decrease in the fiber length, as previously reported [6,7], and therefore in the aspect ratio. These results are in agreement with published data, where the LDPE composites with unmodified fibers presented better mechanical properties than those with fibers esterified for $4 \mathrm{~h}$ in toluene with dodecanoyl and octadecanoyl chloride [12].

Moreover, the storage modulus increased considerably with the filler content (Fig. 2C), as previously observed with other cellulosebased composites [12,21-23].

The effect of the fiber loading, DS and fatty acid chain length on the large strain behavior of cellulose fibers/LDPE composites was investigated up to their failure. The Young modulus, determined from the typical stress-strain curve, increased considerably with the fiber content and, for composites with the same fiber loading, the presence of modified fibers gave higher values than that associated with the unmodified counterparts (Fig. 3A). These results were in perfect agreement with the DMA essays.

Additionally, the presence of fibers caused a considerable decrease in the elongation at break (Fig. 3C). Composites filled with cellulose fibers modified in DMF, and with C12 in toluene, displayed higher elongations at break, some of them very close to that of unfilled LDPE, compared with those containing fibers modified in toluene with C6, C18 and C22. These composites, even with lower mechanical performance, are also quite interesting because they could replace unfilled PE in applications where the mechanical performance is not an important requirement, but with the advantage that these materials contain a considerable proportion of a renewable and biodegradable component.

\section{Morphology}

SEM micrographs of the fractured surface of the composites resulting from tensile tests are shown in Fig. 4. For each material, two different magnifications were used to display both the fiber dispersion and the interfacial adhesion.

Fig. 4A corresponds to the unmodified fibers in a LDPE matrix and clearly shows that the interfacial adhesion between the cellulose fibers and the matrix was very poor. The fibers were pulled out from the matrix practically intact and therefore, fracturing the composite sample did not lead to any substantial fiber breakage. Moreover, the presence of cellulose fiber aggregates, some of them visible with the naked eyes, provided strong evidence of the poor dispersion of the reinforcement within the polymeric matrix and consequently of the non-homogeneity of the material.

Conversely, SEM images of all modified fiber-based composites (Fig. 4B-C) provided evidence of the strong interfacial adhesion between the two components, as shown by the cellulose fibers breaking during fracture and also by their good dispersion within 
the matrix, without aggregates formation. This behavior is the result of the surface acylation that conferred a non-polar character to the cellulose fiber surface [6,7]. Similar results were observed for cellulose fibers with different fatty moieties and DS values, which corroborates the surface energy values previously reported $[6,7]$.

Finally, the composites with cellulose fibers modified in DMF (higher DS), and with C12 in toluene for $6 \mathrm{~h}$, showed a more uniform morphology (Fig. 4C), i.e. the fibers were less visible because they were buried more effectively in the LDPE. As previously reported, the cellulose modification with fatty acids in DMF (and with $\mathrm{C} 12$ in toluene for long reaction times) leads to extensive degradation of the fiber ultrastructure and morphology [6], which probably gives rise to a better compatibility of the fibers with the matrix during the composite processing.

\section{Water uptake}

The water absorption results are crucial for understanding the performance of cellulose-based composites, since the moisture pickup under immersion in water or exposure to high humidity, intimately relates to such composite properties as mechanical strength, dimensional stability and appearance.

Fig. 5 shows the water uptake evolution for unmodified and acylated cellulose-based composites as a function of time. All the composites absorbed water during the experiment, but following quite different profiles. Since PE only showed a very small amount of water uptake after 3 months owing of its hydrophobic nature, the water uptake of the composites was entirely due to the presence of the natural fibers.

Water uptake was considerably higher for unmodified cellulose-based composites, compared with that of their acylated cellulose counterparts. This behavior clearly reflected the presence of long chain aliphatic moieties onto the fibers surface, after esterification with the fatty acyl chlorides, resulting in a considerable increase in their hydrophobic character, as previously reported [6,7]. However, for the acylated cellulose-based composites, the water uptake was not influenced to a great extent by the fatty acid chain length and DS, except of course for very low DS values (i.e. PEC182hT and PEC22hT samples). These observations are in good agreement with previously reported water contact angle measurement and surface energy determinations, where it was observed that the surface energy decreased only slightly with the fatty acid chain length and the DS [6,7].

Moreover, after this ageing period, only the composites with modified fibers (except those with very low DS) had reached an equilibrium moisture level. These samples exhibited a water up-

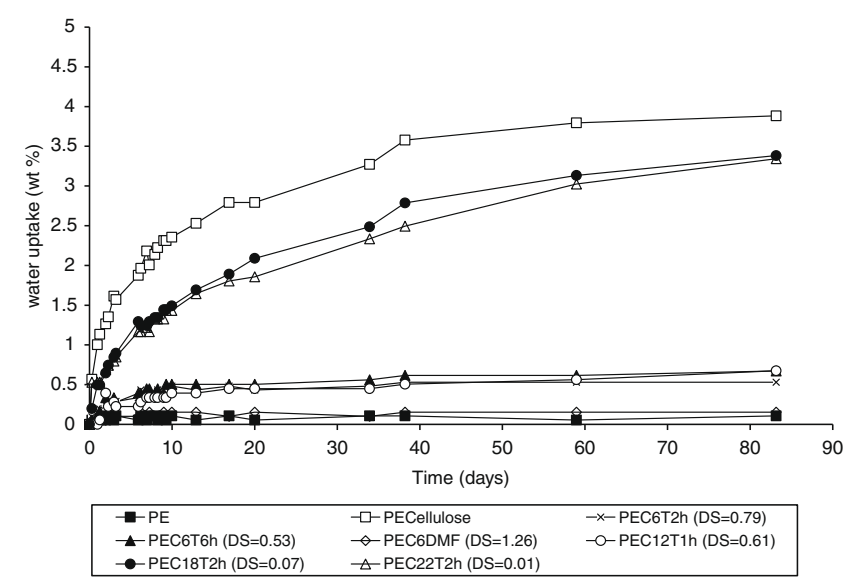

Fig. 5. Water uptake as a function of time for LDPE-cellulose-based composites when immersed in water at room temperature. take pattern with two well-separated regions. Initially, the absorption was fast and followed a linear Fickian behavior before reaching an equilibrium plateau.

\section{Conclusions}

Composite materials were obtained by compounding unmodified and fatty acid-esterified cellulose fibers with low-density polyethylene. The surface chemical modification of the cellulose fibers resulted in improved interfacial adhesion between the fibers and the matrix and consequently in enhanced mechanical properties, as well as in a better water resistance. The results obtained clearly demonstrate the importance of a strict DS control in order to achieve better composite performances. Depending on the properties of the modified fibers (e.g. DS and morphology) these composites, incorporating a cheap and ubiquitous renewable resource, could have different potential applications, namely as structural materials (building or automotive) or packaging materials.

\section{Acknowledgement}

Thanks are due to CICECO for financially supporting this research.

\section{References}

[1] Klemm D, Heublein B, Fink HP, Bohn A. Cellulose: fascinating biopolymer and sustainable raw material. Angew Chem Int Ed 2005;44(22):3358-93.

[2] Gandini A, Belgacem MN, editors. Monomers, polymers and composites from renewable resources. Great Britain: Elsevier; 2008.

[3] Belgacem MN, Gandini A. The surface modification of cellulose fibres for use as reinforcing elements in composite materials. Compos Interfaces 2005;12(12):41-75.

[4] Jandura P, Riedl B, Kokta BV. Thermal degradation behavior of cellulose fibers partially esterified with some long chain organic acids. Polym Degrad Stab 2000;70(3):387-94.

[5] Pasquini D, Belgacem MN, Gandini A, Curvelo AAD. Surface esterification of cellulose fibers: characterization by DRIFT and contact angle measurements. J Colloid Interface Sci 2006;295(1):79-83.

[6] Freire CSR, Silvestre AJD, Neto CP, Belgacem MN, Gandini A. Controlled heterogeneous modification of cellulose fibers with fatty acids: effect of reaction conditions on the extent of esterification and fiber properties. J Appl Polym Sci 2006;100(2):1093-102.

[7] Freire CSR, Silvestre AJD, Neto CP, Gandini A, Fardim P, Holmbom B. Surface characterization by XPS, contact angle measurements and ToF-SIMS of cellulose fibers partially esterified with fatty acids. J Colloid Interface Sci 2006;301(1):205-9.

[8] Matsumura H, Glasser WG. Cellulosic nanocomposites. II. Studies by atomic force microscopy. J Appl Polym Sci 2000;78(13):2254-61.

[9] Matsumura H, Sugiyama J, Glasser WG. Cellulosic nanocomposites. I. Thermally deformable cellulose hexanoates from heterogeneous reaction. J Appl Polym Sci 2000;78(13):2242-53.

[10] Jandura P, Kokta BV, Riedl B. Cellulose fibers/polyethylene hybrid composites: effect of long chain organic acid cellulose esters and organic peroxide on rheology and tensile properties. J Reinf Plast Compos 2001;20(8):697-717.

[11] Jandura P, Riedl B, Kokta BV. Inverse gas chromatography study on partially esterified paper fiber. J Chromatogr A 2002;969(1-2):301-11.

[12] Pasquini D, Teixeira EDM, Curvelo A, Belgacem MN, Dufresne A. Surface esterification of cellulose fibres: processing and characterisation of lowdensity polyethylene/cellulose fibres composites. Compos Sci Technol 2008;68(1):193-201.

[13] Cunha AG, Freire CSR, Silvestre AJD, Neto CP, Gandini A. Reversible hydrophobization and lipophobization of cellulose fibers via trifluoroacetylation. J Colloid Interface Sci 2006;301(1):333-6.

[14] Cunha AG, Freire CSR, Silvestre AJD, Neto CP, Gandini A, Orblin E, et al. Highly hydrophobic biopolymers prepared by the surface pentafluorobenzoylation of cellulose substrates. Biomacromolecules 2007;8(4):1347-52.

[15] Cunha AG, Freire CSR, Silvestre AJD, Neto CP, Gandini A, Orblin E, et al. Characterization and evaluation of the hydrolytic stability of trifluoroacetylated cellulose fibers. J Colloid Interface Sci 2007;316(2):360-6.

[16] Cunha AG, Freire CSR, Silvestre AJD, Neto CP, Gandini A, Orblin E, et al. Biphobic cellulose fibers derivatives via surface trifluoropropanoylation. Langmuir 2007;23(21):10801-6.

[17] Freire CSR, Silvestre AJD, Neto CP, Rocha RMA. An efficient method for determination of the degree of substitution of cellulose esters of long chain aliphatic acids. Cellulose 2005;12(5):449-58. 
[18] Luo S, Netravali AN. Mechanical and thermal properties of environmentfriendly "green" composites made from pineapple leaf fibers and poly(hydroxybutyrate-co-valerate) resin. Polym Compos 1999;20(3):367-78.

[19] Reinsch VE, Kelley SS. Crystallization of poly(hydroxybutyrate-cohydroxyvalerate) in wood fiber-reinforced composites. J Appl Polym Sci 1997;64(9):1785-96.

[20] Favier V, Chanzy H, Cavaille JY. Polymer nanocomposites reinforced by cellulose whiskers. Macromolecules 1995;28(18):6365-7.
[21] Arbelaiz A, Fernandez B, Ramos JA, Retegi A, Llano-Ponte R, Mondragon I. Mechanical properties of short flax fibre bundle/polypropylene composites: influence of matrix/fibre modification, fibre content, water uptake and recycling. Compos Sci Technol 2005;65(10):1582-92.

[22] Bledzki AK, Reihmane S, Gassan J. Thermoplastics reinforced with wood fillers: a literature review. Polym Plast Technol Eng 1998;37(4):451-68.

[23] Joseph K, Thomas S, Pavithran C. Effect of chemical treatment on the tensile properties of short sisal fibre-reinforced polyethylene composites. Polymer 1996;37(23):5139-49. 